\title{
Free radical scavenger activity of chitosan and its aminated derivative
}

\author{
Tamer M Tamer ${ }^{1 *}$, Katarina Valachová ${ }^{2}$, Mohamed Samir Mohyeldin ${ }^{2}$, Ladislav Soltes ${ }^{3}$ \\ ${ }^{1}$ Polymer research department, Advanced Technology and New Materials Research Institute, City of Scientific Research and Technological Applications. \\ New Borg El- Arab, Alexandria, Egypt. ${ }^{2}$ Laboratory of Bioorganic Chemistry of Drugs, Institute of Experimental Pharmacology and Toxicology, SK-81404 \\ Bratislava, Slovakia. ${ }^{3}$ Chemistry Department, Faculty of Science, University of Jeddah, Osfan, P. O. Box: 80203, Jeddah 21589, Saudi Arabia.
}

\begin{tabular}{l} 
ARTICLE INFO \\
\hline Article history: \\
Received on: $11 / 11 / 2015$ \\
Revised on: $04 / 01 / 2016$ \\
Accepted on: $12 / 02 / 2016$ \\
Available online: $30 / 04 / 2016$ \\
\hline Key words: \\
Chitosan, Aminated chitosan, \\
Antioxidant, Rotational \\
viscometer, ABTS, \\
Hyaluronan \\
\hline
\end{tabular}

\begin{abstract}
Antioxidants may have a positive effect on human health since they can protect the human body against deterioration by reactive oxygen species (ROS). Chitosan has many promising properties as nontoxic, biocompatible, biodegradable, antimicrobial and recently antioxidant properties. Most of the reports on the antioxidant activity of chitosan are based on the ability of amine and hydroxyl group to scavenge free radical to form stable macromolecular radical. In the current study, a new chitosan derivative with extra free amine groups was evaluated using two popular antioxidant evaluation methods (uninhibited/inhibited hyaluronan degradation and decolorization of ABTS method). The result obtained in our study show increase the activity of aminated chitosan for scavenging free radicals than chitosan itself.
\end{abstract}

\section{INTRODUCTION}

The harmful effect of free radicals attracts the attention of the scientist in last few years. The dangerous effect of free radicals reactive oxygen species (ROS) that generated by our body driving scientists to focus their studies on understanding its generation mechanisms, combined diseases and final the best methods to control it. ROS are generated by our body via various endogenous systems, exposure to different physiochemical conditions or pathological states. Generation of superoxide anion radicals, hydroxyl radicals, and hydrogen peroxide, are normal by-products of metabolic processes in cells which may be increased under up normal environmental conditions, and uncontrolled ROS can easily react with a wide range of essential biomolecules, causing damage and ultimately leading to cell death (Anselmo and Cobb., 2004; Baek et al., 2008; Waris and Ahsan., 2006; Fernandes et al., 2010). A balance between free radicals and antioxidants is necessary for

\footnotetext{
* Corresponding Author

Tamer M Tamer, Polymer research department, Advanced Technology and New Materials Research Institute, City of Scientific Research and Technological Applications. New Borg El-Arab, Alexandria, Egypt. Email:ttamer85@gmail.com
}

proper physiological function. (Lobo et al., 2010). Scavengers of free radicals are preventive antioxidants, as they can break the oxidative sequence by delaying or preventing ROS generation, and by competing for existing radicals and removing them from the reaction, thus protecting biomolecules from damage (Kim and Rajapakse., 2005; Xiong et al., 2007). Chitosan is biocompatible, biodegradable, nontoxic, renewable biopolymer produced by alkali treatment of chitin the second most abundant natural polysaccharide next to cellulose and found in the composition of crustacean shells. Chitin consists of $\beta(1 \rightarrow 4)$-2-acetamido-2deoxy-d-glucopyranose (GlcNAc) as a repeating unit. Deacetylation of chitin yields chitosan, which is a copolymer GlcNAc and $B$-( $1 \rightarrow 4)$-2-amino-2-deoxy-d-glucopyranose with deacetylation greater than $60 \%$. Chitosan has a broad field applications ranging from cosmetics, artificial skin, photography, food and nutrition, wound dressing, ophthalmology and wastewater treatment (Kumar et al., 2007; Shahidi et al., 2004; Dodane et al., 1998; Jeon et al., 2000; Mohy Eldin et al 2008a;b; 2013 ; 2015). The unique properties of chitosan over the other polysaccharide were attributed to free amine groups that give it its basic character.

In this study, antioxidant evaluation of chitosan and extra- aminated chitosan was performed. 


\section{MATERIALS AND METHODS}

\section{Materials}

Chitin from crab shells, the practical grade, was obtained from Sigma- Aldrich Chemicals Ltd. (Germany), acetic acid (purity 99.8\%), p-benzoquinone (PBQ) (purity 99\%), and sodium hydroxide pellets (purity 99-100\%,) were obtained from SigmaAldrich (Germany). EDA (purity 99\%) was obtained from Alfa Aesar (Germany). The high-molar-mass hyaluronan sample Lifecore P9710-2A, kindly donated by Lifecore Biomedical Inc., Chaska, MN, USA (Mr 808.7 kDa; Mr/Mn¹/41.63), was used on experiments. The analytical purity grade $\mathrm{NaCl}$ and $\mathrm{CuCl}_{2} \cdot 2 \mathrm{H}_{2} \mathrm{O}$ (Slavus Ltd., SK-Bratislava); L-ascorbic acid and $\mathrm{K}_{2} \mathrm{~S}_{2} \mathrm{O}_{8}$ (p.a. purity, max $0.001 \%$ nitrogen; Merck, Germany); 2, 2'-azinobis (3ethylbenzothiazoline-6-sulfonic acid) (ABTS; purum, >99\%; Fluka, Germany) were used.

\section{Methods}

\section{Preparation of aminated chitosan}

Aminated chitosan derivative was prepared according to our previous work (Mohy Eldin et al., 2012). In detail, $4 \mathrm{~g}$ of chitin was dispersed in $50 \mathrm{~mL}$ of $(6.9 \mathrm{mM}) \mathrm{p}$ - benzoquinone (PBQ) - distilled water solution at $\mathrm{pH} 10$ and $60{ }^{\circ} \mathrm{C}$ and was stirred for $6 \mathrm{~h}$. The PBQ-conjugated chitin was separated and washed with distilled water to remove unreacted PBQ.

In the second step, $\mathrm{PBQ}$-conjugated chitin was dispersed in $50 \mathrm{~mL}$ of $(6.9 \mathrm{mM})$ EDA-distilled water at $60{ }^{\circ} \mathrm{C}$ and stirred for $6 \mathrm{~h}$. The aminated modified chitin was separated and washed with distilled water to remove unreacted EDA.

In the last step, aminated modified chitin was deacetylated according to the method of Rigby and Wolfarn. The aminated modified chitin derivative was treated with $50 \%$ aqueous solution of $\mathrm{NaOH}$ at $120-150^{\circ} \mathrm{C}$ for $12 \mathrm{~h}$ (see figure 1). The obtained aminated chitosan derivatives were separated and washed with distilled water to remove excess of $\mathrm{NaOH}$.

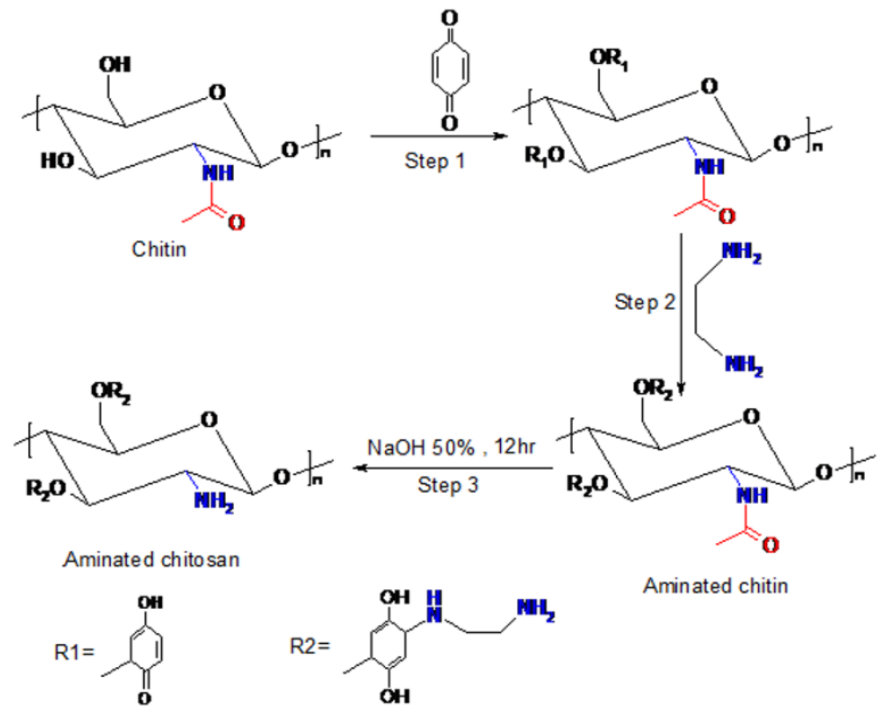

Fig. 1: Preparation of aminated chitosan.

\section{Antioxidant evaluation}

\section{ABTS method}

For the ABTS decolorization assay, the radical cations were pre-formed by the reaction of an aqueous solution of $\mathrm{K}_{2} \mathrm{~S}_{2} \mathrm{O}_{8}$ (3.30 mg) in $\mathrm{H}_{2} \mathrm{O}(5 \mathrm{ml})$ with ABTS $(17.2 \mathrm{mg})$.

The resulting bluish green radical cation solution was stored overnight in the dark below $0{ }^{\circ} \mathrm{C}$. Before the experiment, the solution. $(1 \mathrm{ml})$ was diluted with a final volume $(60 \mathrm{ml})$ acetic acid solution $(0.5 \%)$.

chitosan (or aminated chitosan) solution $(0.5 \%)$ stock solutions were prepared in acetic acid (0.5\%). A modified ABTS assay (Rapta et al., 2009) was used to test the radical-scavenging efficiency applying a UV-1800 spectrophotometer (SHIMADZU, Japan).

The UV/VIS spectra were recorded at defined times, in $1 \mathrm{~cm}$ quartz UV cuvette after mixing of antioxidant solution $(50 \mu \mathrm{l})$ with an ABTS. soln. $(2 \mathrm{ml})$.

\section{Rotational viscometry method}

For the rotational viscometry measurements, a hyaluronan soln. $(2.5 \mathrm{mg} / \mathrm{ml})$ was prepared in the dark, standing at room temperature in an aqueous. $\mathrm{NaCl}$ soln. $(0.15 \mathrm{mM})$ in two steps: first, the solvent $(4.0 \mathrm{ml})$ was added to a hyaluronan powder $(20 \mathrm{mg})$, and, within $6 \mathrm{~h}$, the same solvent $(3.85 \mathrm{ml})$ was added. The stock solutions $(16 \mu \mathrm{M})$ of ascorbic acid, Polymer solution $(0.5 \%)$ stock solutions were prepared in acetic acid $(0.5 \%) . \mathrm{CuCl}_{2}$ $(160 \mu \mathrm{M})$ were also prepared.

Before starting to monitor the kinetics of the hyaluronan degradation via rotational viscometry, the mixture $(8.0 \mathrm{ml})$, consisting of the biopolymer solution of the concentration as stated above, ascorbic acid $(100 \mu \mathrm{M}), \mathrm{Cu}$ II ions $(1.0 \mu \mathrm{M})$, and certain amount of chitosan (or aminated chitosan) solution were transferred into the Teflon cup reservoir of the Brookfield LVDVIIPRO digital rotational viscometer (Brookfield Engineering Labs., Inc., Middleboro, MA, USA).

The experimental set was carried out by adding the chitosan (or aminated chitosan) solution at the beginning of degradation and also after 1 hour of degradation start. The Data acquisition of the viscometer output parameters was performed by recording within 2 min after the onset of the experiment.

Time-dependent changes of the dynamic viscosity values of the system were measured at $25.0 \pm 0.1$ within 3 min intervals for up to $5 \mathrm{~h}$. The viscometer Teflon spindle rotation rate was 180 $\mathrm{rpm}$, i.e., at the shear rate equaling $237.6 \mathrm{~s}^{-1}$. (Soltes et al., 2005; 2007)

\section{RESULTS}

\section{Antioxidant evaluation}

In this study antioxidant of chitosan and aminated chitosan were done by measuring hydroxyl and alkyl free radical scavenger activity via rotational viscometry method beside measure the free radical scavenger activity via ABTS method. 


\section{Rotational viscometry method}

Rotational viscosity of hyaluronan was studied under free radical degradation condition (i.e.; by the Weissberger's oxidative system) in presence and absence of chitosan or aminated chitosan. This standardized method is, in general, used to mimic the pathophysiological situation, which may occur at the early stage of acute joint inflammation. The chief advantage of rotational viscometry is the possibility to carry continuously out measurements at a given shear rate over extended periods of time. (Hrabarova et al., 2010). Applied Weissberger's system (ascorbic acid and $\mathrm{Cu}$ II) in aerobic conditions generate $\mathrm{HO}^{\bullet}$ See Figure (2).

By application of Weissberger's system, the hyaluronan degradation was evidenced by the gradual decline of its dynamic viscosity. Attacking of hydroxyl free radicals to hyaluronan backbone eliminate hydrogen atom from it that leaving the free radical on the chain. Under aerobic condition splitting chains will appear, Figure 3. Figure (4) showed the effect of the addition of chitosan and aminated chitosan solution (in acetic acid) atin the beginning of the test. It can show increase the rate of hyaluronan degradation in acidic condition that may be attributed to catalytic effect of $\mathrm{H}^{+}$in production of ${ }^{\circ} \mathrm{OH}$ radicals from Weisberg's oxidation system. Chitosan and aminated chitosan show relatively moderated hydroxyl radical scavenger in this conditions. Figure (5) show the effect of chitosan and aminated chitosan on the degradation kinetics when it adds after one hour of the test begging. At this time, the hydroxyl radicals will be consumed in hyaluronan degradation, and the dominated free radicals are alkoxyl, peroxyl and hyaluronan macroradicals that generated through propagation step (Valachová et al., 2011; Hrabarova et al., 2012). According to uninhibited/inhibited hyaluronan degradation method, the concept of antioxidant evaluation focused on scavenger of hydroxyl or alkoxyl radicals. The strategy of scavenging of these free radicals comes through donating hydrogen atom. The scavenging activities of chitosan derivatives against ${ }^{\circ} \mathrm{OH}$ may be derived from some or all of the following:

i. The hydroxyl groups in the polysaccharide unit can react with ${ }^{\circ} \mathrm{OH}$ by the typical $\mathrm{H}$-abstraction reaction.

ii. ${ }^{\circ} \mathrm{OH}$ can react with the residual free amino groups $\mathrm{NH}_{2}$ to form stable macromolecule radicals. (Xie et al., 2001)

In our testing material, the ideal source of hydrogen atom coming from $-\mathrm{NH}_{2}$ and $-\mathrm{OH}$ groups that distributed along the backbone of the polymer, under acidic condition $(\mathrm{pH} \sim 4)$ amine groups in chitosan protonated, that decrease its contribution to scavenge radical hydroxyl compared to hydroxyl groups. So, decrease the scavenger activity of aminated chitosan rather than chitosan itself may be explained on the idea of consumption of hydroxyl group in amination process.
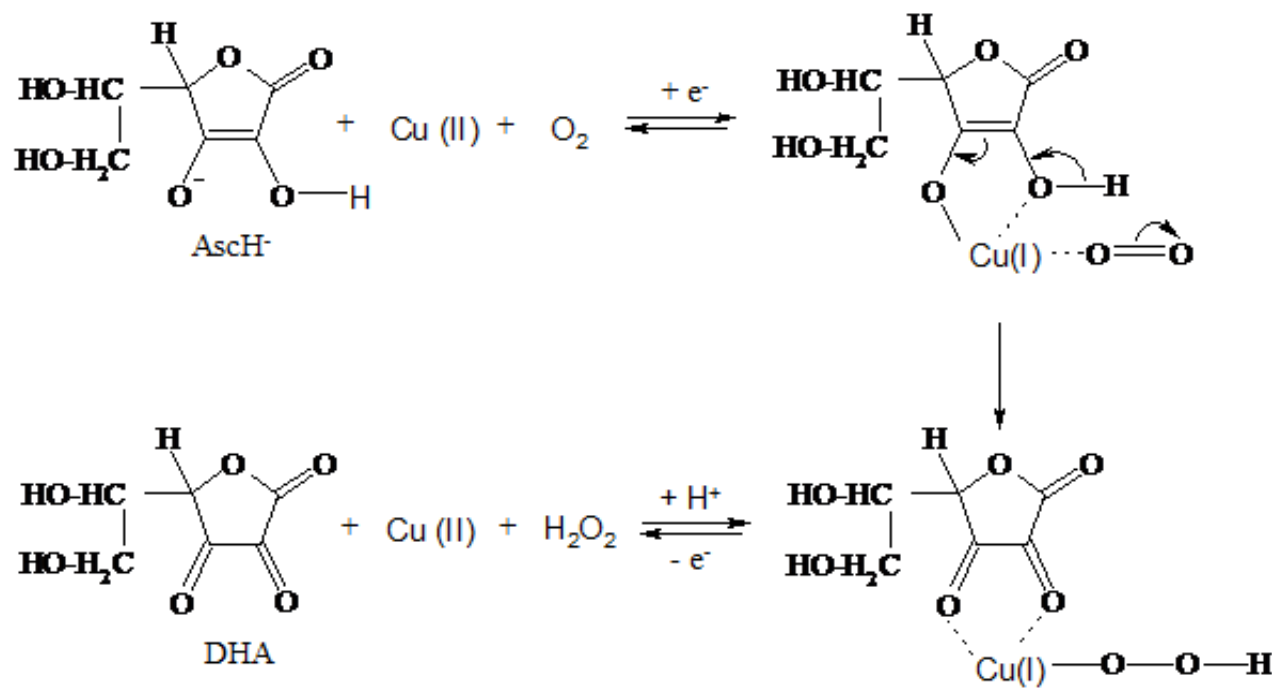

$\mathrm{H}_{2} \mathrm{O}_{2}+\mathrm{Cu}(\mathrm{I}) \ldots$ complex $\longrightarrow{ }^{\circ} \mathrm{OH}=\mathrm{HO}^{-}+\mathrm{Cu}(\mathrm{II}) \ldots$ Complex

Fig. 2: Weissberger's biogenic oxidation system (WBOS) (Fisher and Naughton., 2005). 

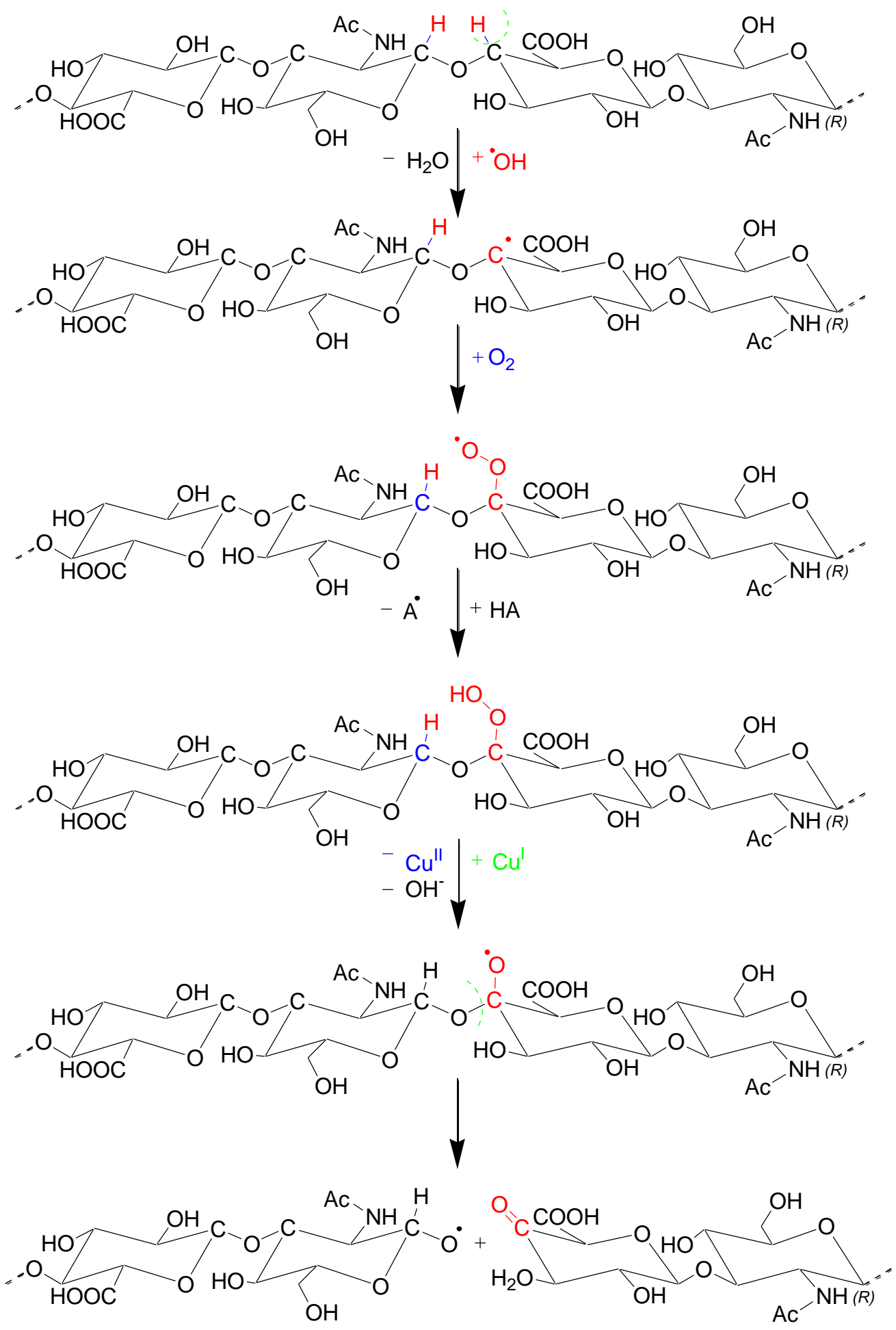

Fig. 3: Schematic degradation of HA under free radical stress (Hrabarova et al., 2012) 


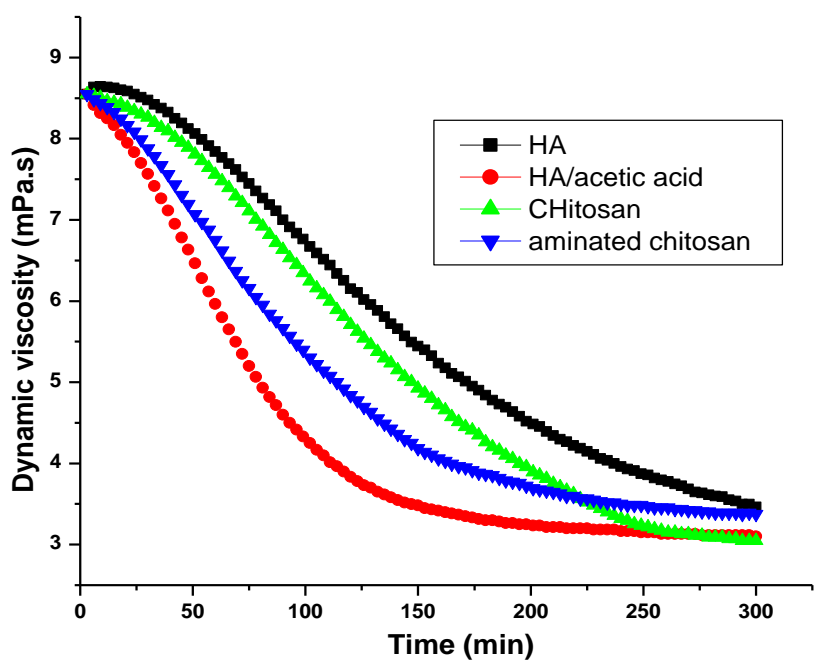

Fig. 4: Effect of chitosan and aminated chitosan dissolved in acetic acid $(0.5 \%)$ on the hyaluronan degradation induced by WBOS (black) when added to the reaction system before initiating the degradation of HA.

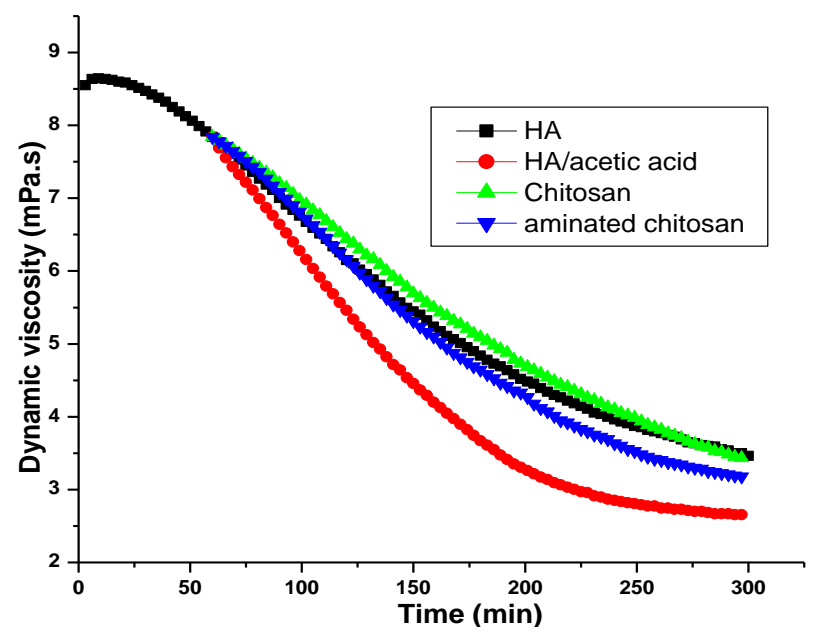

Fig. 5: Effect of chitosan and aminated chitosan dissolved in acetic acid $(0.5 \%)$ on the hyaluronan degradation induced by WBOS (black) when added to the reaction system after 1 hour of initiating the degradation of HA.
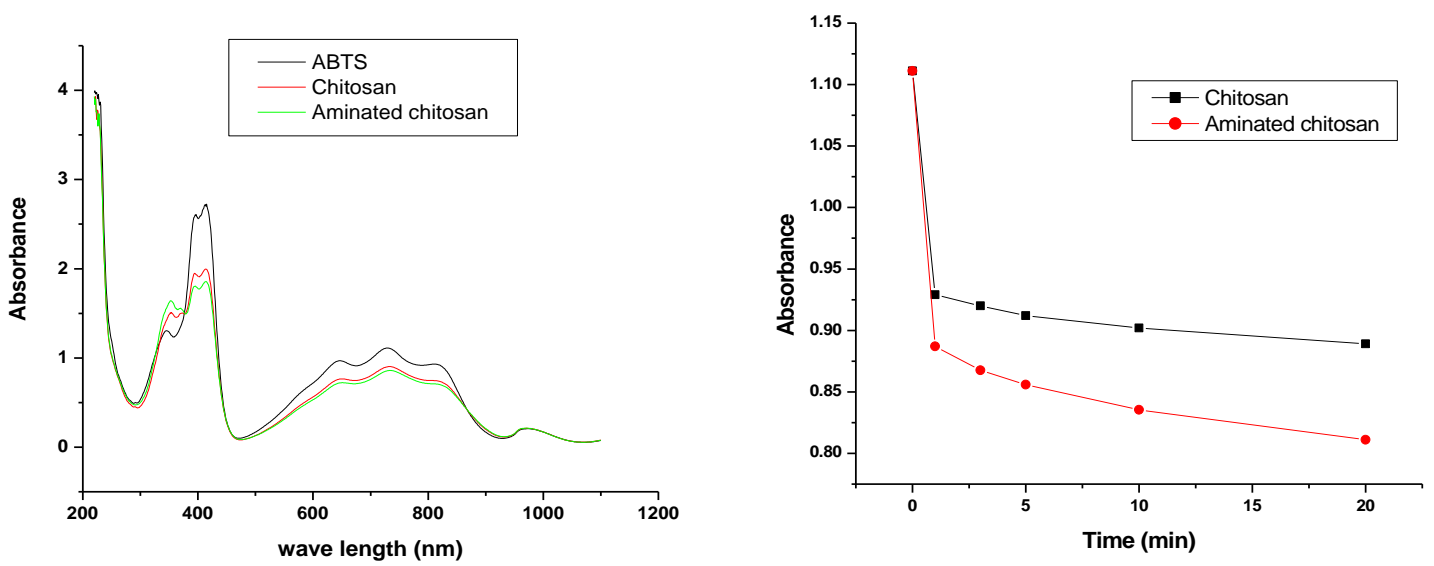

Fig. 6: Effect of chitosan and aminated chitosan (conc $0.125 \mathrm{mg} / \mathrm{ml}$ ) on reducing ABTS ${ }^{++}$cation radical measured 10 min after the reaction onset (at wavelength $730 \mathrm{~nm}$ ). In right panel, Time dependence of absorbance at $730 \mathrm{~nm}$ measured after addition of polymer solution into the ABTS ${ }^{++}$

\section{ABTS Method}

\section{In this method}

ABTS (2,2'-azinobis-(3-ethylbenzothiazoline- 6-sulfonic acid)) radical cation (Wolfenden and Willson., 1982) forms the basis of one of the spectrophotometric methods that have been applied to the measurement of the total antioxidant activity of solutions of pure substances (Rice-Evans and Miller., 1995; RiceEvans et al., 1995; Miller et al., 1996), aqueous mixtures and beverages (Salah et al., 1995). Decolorization of $\mathrm{ABTS}^{++}$bluish green color was taken as a monitor for measuring the ability of an antioxidant to donating an electron. $\mathrm{ABTS}^{\circ+}$ exhibits a bluishgreen color with maximum absorbance values at 645, 730, and $815 \mathrm{~nm}$, this color rapidly decrease by an acceptant electron from antioxidant substance (Hrabarova et al., 2010; Re et al., 1999).
Figure (6) show the effect of chitosan and aminated chitosan in decolorization of $\mathrm{ABTS}^{++}$color. It can recognise the scavenger activity of aminated chitosan more than that for chitosan itself. Figure (6) Show the time dependency of decolorization activity of polymer.

The dose-response curve obtained by analysis of a range of concentrations of chitosan and aminated chitosan was measured and presented in figure $(7,8)$. It was clear increase the removing activity by increasing concentration.

Several mechanisms were stated to explain the antioxidant activity of chitosan (Xue et al., 1998; Muzzarelli et al., 1997; Park et al., 2004; Sousa et al., 2004). The most suitable one is the interaction of free radical with hydroxyl or amine group to form stable macromolecule radicals (Xie et al., 2001). 

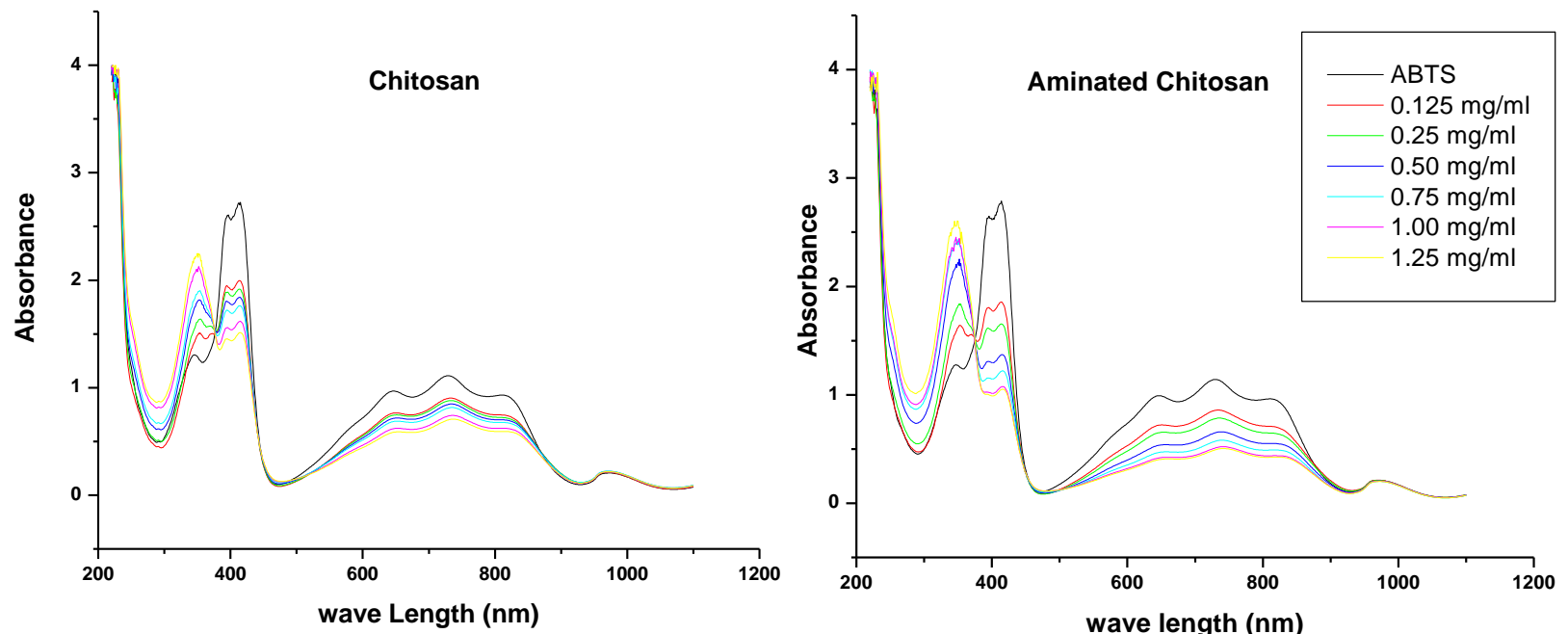

Fig. 7: Effect of chitosan and aminated chitosan concentration on reducing $\mathrm{ABTS}^{+}$cation radical measured 10 min after the reaction onset (at wavelength $730 \mathrm{~nm})$

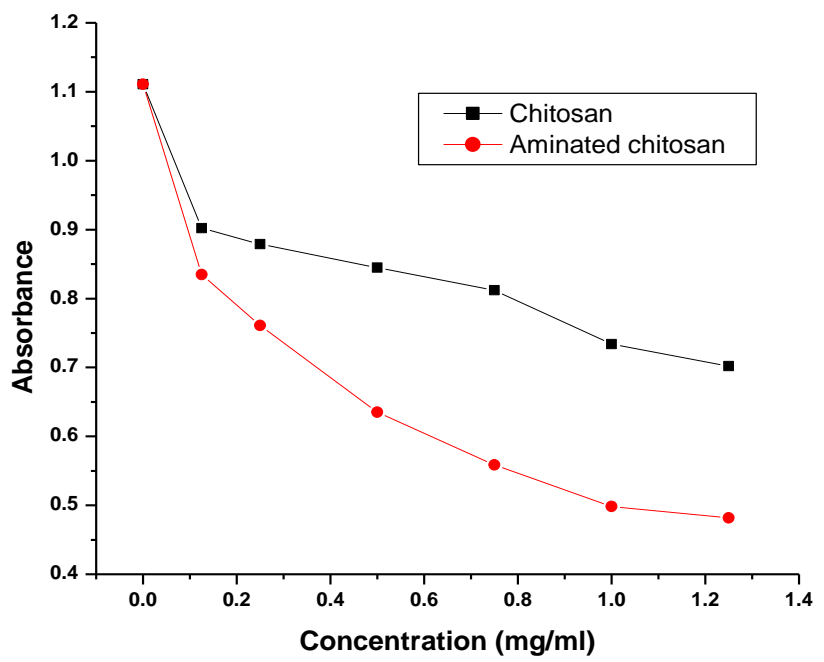

Fig. 8: Dose dependency of $\mathrm{ABTS}^{++}$cation scavenging activity of chitosan and aminated chitosan measured 10 min after the reaction onset (at wavelength 730nm). The activity of $\mathrm{ABTS}^{*+}$ by aminated chitosan rather than chitosan itself. That may be attributed to increasing ability to donate electron as a direct result of increasing amine groups.

\section{CONCLUSION}

The results show that free radical scavenging activity of chitosan was increased via amination process. Promotion of antioxidant activity may be attributed to replacing hydroxyl groups with free amine groups. Obtained results confirm functionality of antioxidant potency of chitosan.

\section{REFERENCES}

Anselmo A N, Cobb M H. Protein kinase function and glutathionylation. Biochemistry Journal., 2004; 381: e1-e2.

Baek D, Jin Y, Jeong J C, Lee H J, Moon H, Lee J. Suppression of reactive oxygen species by glyceraldehyde-3-phosphate dehydrogenase. Phytochemistry., 2008; 69: 333-338.

Dodane V, Vilivalam V D. Pharmaceutical applications of chitosan. Pharm. Sci. Technol. Today., 1998; 1: 246-253.

Fernandes J C, Eaton P, Nascimento H, Gião M S, Ramos O S, Belo L, Silva A S, Pintado M E, Malcata F X. Antioxidant activity of chitooligosaccharides upon two biological systems: Erythrocytes and bacteriophages. Carbohydr. Polym., 2010; 79: 1101-1106.

Fisher A E O, Naughton D P. Therapeutic chelators for the twenty first century: new treatments for iron and copper mediated inflammatory and neurological disorders. Curr. Drug Delivery., 2005; 2 (3): 261-268.

Hrabarova E, Valachova K, Juranek I, Soltes L. Free-Radical Degradation of High-Molar-Mass Hyaluronan Induced by Ascorbate plus Cupric Ions: Evaluation of Antioxidative Effect of Cysteine- Derived Compounds. CHEMISTRY \& BIODIVERSITY., 2012; 9: 309-317.

Hrabarova E, Valachova K, Rapta P, Soltes L. An Alternative Standard for Trolox-Equivalent Antioxidant-Capacity Estimation Based on Thiol Antioxidants. Comparative 2,2'-Azinobis(3- ethylbenzothiazoline-6sulfonic Acid) Decolorization and Rotational Viscometry Study Regarding Hyaluronan Degradation. Chem Biodivers., 2010; 7(9):2191-2200.

Jeon Y J, Shahidi F, Kim S K. Preparation of chitin and chitosan oligomers and thir application in physiological functional foods. Food Rev. Int., 2000; 16: 159-176.

Kim S K, Rajapakse N. Enzymatic production and biological activities of chitosan oligosaccharides (COS): A review. Carbohydrate Polymers., 2005; 62: 357-368. 
Kumar M N, Muzzarelli R A, Muzzarelli C, Sashiwa H, Domb A J. Chitosan Chemistry and Pharmaceutical Perspectives. Chem. Rev., 2004; 104: 6017-6084.

Lobo V., Patil A., Phatak A., Chandra N. Free radicals, antioxidants and functional foods: Impact on human health. Pharmacogn Rev., 2010; 4(8):118-126.

Miller N J, Sampson J, Candeias L P, Bramley P M, Rice-Evans C A. Antioxidant activities of carotenes and xanthophylls. FEBS Lett., 1996; 384:240-242.

Mohy Eldin M S, Hashem A I, Omer A M, Tamer, T M. Wound dressing membranes based on chitosan: Preparation, characterization and biomedical evaluation. International Journal of Advanced Research., 2015; 3 (8): 908- 922.

Mohy Eldin M S, Soliman E A, Hashem A I, Tamer T M. Chitosan Modified Membranes for Wound Dressing Applications: Preparations, Characterization and Bio-Evaluation. Trends Biomater. Artif. Organs., 2008a; 22: 154-164.

Mohy Eldin M S, Soliman E A, Hashem A I, Tamer T M. Antibacterial Activity of Chitosan Chemically Modified with New Technique. Trends Biomater. Artif. Organs., 2008b; 22: 121-133.

Mohy Eldin M S, Soliman E A, Hashem A I, Tamer T M. Antimicrobial Activity of Novel Aminated Chitosan Derivatives for Biomedical Applications. Advances in Polymer Technology., 2012; 31: 414-428.

Mohy Eldin M S, Soliman E A, Hashem A I, Tamer T M, Sabet M M. Antifungal Activity of aminated Chitosan against three different fungi species. Key Engineering Materials- Current State-of-the-Art on Novel Materials. 2013; Vol 1, Ch 26, ISBN: 9781926895734.

Muzzarelli R A A, Muzzarelli C M, Terbojerich M. Chitin chemistry, upgrading a renewable source. Carbohydr European., 1997; 19: $10-7$.

Park P J, Je J Y, Kim S W. Free radical scavenging activities of different deacetylated chitosans using ESR spectrometer. Carbohydr Polym., 2004; 55: 17-22.

Rapta P, Valachova K, Gemeiner P, Soltes L. High-Molar-Mass Hyaluronan Behavior During Testing Its Radical Scavenging Capacity in Organic and Aqueous Media: Effects of the Presence of Manganese(II) Ions. Chem. Biodiversity., 2009; 6: 162-169.

Re R, Pellegrini N, Proteggente A, Pannala A, Yang M, RiceEvans C. Antioxidant activity applying an improved ABTS radical cation decolorization assay.Free Radic Biol Med. May; 1999; 26(9-10): 1231-7.

Rice-Evans C A, Miller N J, Bolwell G P. Bramley P M, Pridham J B. The relative antioxidant activities of plant-derived polyphenolic flavonoids. Free Radic. Res., 1995;22:375-383.

Rice-Evans C A, Miller N J. Antioxidants-the case for fruit and vegetables in the diet. Brit. Food J., 1995; 97: 35-40.
Salah N, Miller N J, Paganga G, Tijburg L, Rice-Evans, C A. Polyphenolic flavonols as scavengers of aqueous phase radicals and as chain-breaking antioxidants. Arch. Biochem. Biophys., 1995; 322:339346.

Shahidi F, Arachchi J K V, Jeon Y. Food application of chitin and chitosan. Trends Food Sci. Technol., 1999;10: 37-51.

Soltes L, Kogan G, Stankovska M, Mendichi R, Rychly J, Schiller J, Gemeiner P. Degradation of high-molar-mass hyaluronan and characterization of fragments Biomacromolecules., 2007; 8(9): 2697-2705.

Soltes L, Stankovska M, Kogan G, Gemeiner P, Stern R. Contribution of oxidative-reductive reactions to high-molecular-weight hyaluronan catabolism. Chem. Biodiversity., 2005; 2: 1242-1246.

Sousa F, Guebitz G M, Kokol V. Antimicrobial and antioxidant properties of chitosan enzymatically functionalized with flavonoids. Process Biochemistry., 2009; 44: 749-756.

Valachová K, Vargová A, Rapta P, Hrabárová E, Dráfi F, Bauerová K, Juránek I, Soltés L. Aurothiomalate as preventive and chainbreaking antioxidant in radical degradation of high-molar-mass hyaluronan.Chem Biodivers., 2011; 8 (7):1274-83.

Waris G, Ahsan H. Reactive oxygen species, role in the development of cancer and various chronic conditions. Journal of Carcinogenesis., 2006; 5: 1-8.

Wolfenden B S, Willson R L. Radical-cations as reference chromogens in kinetic studies of one-electron transfer reactions: pulse radiolysis studies of 2,2'-azinobis-(3-ethylbenzthiazoline-6-sulphonate). J. Chem. Soc. Perkin Trans., 1982; 2: 805-812.

Xie W, Xu P, Liu Q. Antioxidant activity of a water-soluble chitosan derivates. Bioorg Med Chem Lett., 2001; 11: 1699-701.

Xiong S L, Li A L, Jin Z Y, Chen M. Effects of oral chondroitin sulfate on lipid and antioxidant metabolisms in rats fed a highfat diet. Journal of Food Biochemistry., 2007; 31: 356-369.

Xue C, Yu G T, Hirata J, Terao J, Lin H. Antioxidative activities of several marine polysacharides evaluated in a phosphatidylcholine-liposomal suspension and organic solvents. Biosci Biotech Biochem., 1998; 62: 206-209.

\section{How to cite this article:}

Tamer TM, Valachová K, Mohyeldin MS, Soltes L. Free radical scavenger activity of chitosan and its aminated derivative. J App Pharm Sci, 2016; 6 (04): 195-201. 